\title{
Interfacial Intermetallic Growth and Strength of Composite Lead-Free Solder Alloy Through Isothermal Aging
}

\author{
V.. SIVASUBRAMANIAM, ${ }^{1,2,3}$ N.S. BOSCO, ${ }^{1}$ J. JANCZAK-RUSCH, ${ }^{1}$ \\ J. CUGNONI, ${ }^{2}$ and J. BOTSIS ${ }^{2}$ \\ 1.-Laboratory for Surface and Joining Technology, Swiss Federal Laboratories for Materials \\ Testing and Research (EMPA), Duebendorf 8600, Switzerland. 2--Laboratoire de Mécanique \\ Appliquée et d'analyse de Fiabilité, Ecole Polytechnique Fédérale de Lausanne (EPFL), Lausanne \\ 1015, Switzerland. 3. - e-mail: venkatesh.sivasubramaniam@empa:ch
}

The effects of particle reinforcement of Sn-4.0wt.\%Ag-0.5wt.\%Cu (SAC405) lead-free solder on interfacial intermetallic layer growth and strength of the ensuing joints through short-term isothermal aging $\left(150^{\circ} \mathrm{C}\right)$ were studied. Composite solders were prepared by either incorporating $2 \mathrm{wt} . \% \mathrm{Cu}(3 \mu \mathrm{m}$ to $20 \mu \mathrm{m})$ or $\mathrm{Cu}_{2} \mathrm{O}(\sim 150 \mathrm{~nm})$ particles into SAC405 paste. Aggressive flux had the effect of reducing the $\mathrm{Cu}_{2} \mathrm{O}$ nanoparticles into metallic $\mathrm{Cu}$ which subsequently reacted with the solder alloy to form the $\mathrm{Cu}_{6} \mathrm{Sn}_{5}$ intermetallic. While all solders had similar interfacial intermetallic growth upon reflow, both of the composite solders' growth rates slowed through aging to reach a common growth rate exponent of approximately 0.38 , considerably lower than that of the nonreinforced solder $(n=0.58)$. The nanoscale reinforced solder additionally exhibited the highest tensile strength in both the initial and aged conditions, behavior also attributed to its quick conversion to a stable microstructure.

Key words: Lead-free solder, nanocomposite, aging, intermetallic . compounds, tension test

\section{INTRODUCTION}

Tin (Sn)-rich lead-free solders are currently the predominant interconnection material for the microelectronics industry. The resulting interconnect provides both electrical and mechanical connection between integrated circuit devices and their substrate. ${ }^{1}$ Existing lead-free solders are not dropin substitutes for conventional lead-bearing solders, however, as they have yet to match or surpass current reliability standards. ${ }^{2}$ During the soldering process molten solder wets and reacts with the metallization of the substrate to form a metallurgical bond by the formation of intermetallic compounds. ${ }^{3}$ While adequate formation of this intermetallic layer is essential for good bonding, an overly thick layer promotes a brittle failure mode at

(Received January 3, 2008; accepted May 6, 2008;

published online July 29, 2008) this interface. ${ }^{4}$ The thickening of this layer is due to the constant and inevitable diffusion of Sn from the bulk solder to the substrate primarily during service at high homologous temperatures. Therefore it is of current interest to limit the growth of the interfacial intermetallic such that an optimum layer thickness is achieved: one that ensures a robust bond yet is not conducive to a brittle failure mode. One approach researchers have adopted for this purpose is the composite method, in which suitable particles are introduced to stabilize the solder's microstructure. ${ }^{5}$ The overall objective of the current study is to investigate the effect of adding reactive particles to the solder alloy on the subsequent growth of the interfacial intermetallic layer and the ensuing joint's tensile strength.

To address this objective, two composite solders (solder alloy with additional particles) were fabricated for comparison against the unreinforced alloy through aging at $150^{\circ} \mathrm{C}$ for up to 1 week. Either 
micrometer-scale $\mathrm{Cu}$ or nanometer-scale $\mathrm{Cu}_{2} \mathrm{O}$ particles were employed as the reinforcement particles to subsequently produce additional $\mathrm{Cu}-\mathrm{Sn}$ intermetallic reinforcing phases. The expectation is that the large difference in initial particle size of this additional source of $\mathrm{Cu}$ will help to elucidate the rate-limiting mechanism of the interfacial intermetallics growth. $\mathrm{Cu}$ was also chosen as a reinforcement to increase joint strength without sacrificing ductility; the relatively weak interfacial bonding between $\mathrm{Cu}-\mathrm{Sn}$ particles and the solder matrix, compared with $\mathrm{Ni}$ or inorganic particles for example, is expected to allow more homogenous deformation of the solder joint, therefore preserving its ductility within a range similar to unreinforced Sn-rich lead-free solders. ${ }^{6-8}$ In the current study the mechanical mixing of nanometer-sized $\mathrm{Cu}_{2} \mathrm{O}$ particles is also sought as an alternative to the difficult in situ preparation of composite solders. It is demonstrated that, while a similarly reduced steady state of intermetallic growth is obtained for the two composite samples, it is achieved sooner in the one fabricated with the nanometer-scale particles. Mechanical test results indicate that the composite specimen prepared with nanometer-scale particles also provides the highest tensile strength both before and after aging. A discussion on the implications of these results on the current understanding of composite solder behavior follows.

\section{MATERIALS AND EXPERIMENTAL PROCEDURE}

Three aging specimens were prepared for the current study: one with a reference and two with composite solders. The lead-free solder alloy Sn-4.0wt.\%Ag-0.5wt.\%Cu (SAC405, Alpha Metals) in the form of solder paste was used for the reference specimen and as the matrix material for the two composite solders. The composite solders were prepared by adding either 2 wt. $\%$ micrometer-scale commercial $\mathrm{Cu}$ particles ( $3 \mu \mathrm{m}$ to $20 \mu \mathrm{m}, 99.9 \%$ purity, Leico Industries) or nanometer-scale polyvinylpyrrohdone-coated copper oxide particles $\left(\mathrm{Cu}_{2} \mathrm{O} / \mathrm{PVP}\right)$ to the solder paste with a simple mechanical mixing method. ${ }^{9}$ The $\mathrm{Cu}_{2} \mathrm{O} / \mathrm{PVP}$ particles were synthesized via a chemical reduction route and analyzed for size and composition with electron microscopy and powder $x$-ray diffraction. ${ }^{10}$ Aging specimens were fabricated by reflowing the prepared solders on $\mathrm{Cu}$ substrates $(3 \mathrm{~cm} \times 2 \mathrm{~cm} \times$ $0.2 \mathrm{~cm}$ ) first pohshed to a 1000 grit size, degreased, pickled in a $5 \% \mathrm{HCl}$ solution, rinsed in deionized water, and blown dry. The reaction surface area of the substrates and the amount of solder paste were fixed for each specimen. Reflow soldering was conducted in a Zelflow RO4 oven (LPKF Electronics) with a temperature profile consisting of a $150^{\circ} \mathrm{C}$ preheating stage followed by a peak temperature of $240^{\circ} \mathrm{C}$. The specimens were reflowed individually and removed from the oven to cool in air. Following initial reflow, the specimens were aged in a $150^{\circ} \mathrm{C}$ oven and analyzed at regular intervals of $24 \mathrm{~h}$ for up to 1 week. At these intervals the specimens were sectioned, polished to a $0.6-\mu \mathrm{m}$ finish with a suspension of alumina and etched with $5 \% \mathrm{HCl}$ in methanol to highlight the intermetallic phases. Scanning electron microscopy (SEM) with energydispersive spectroscopy (EDS) was used to characterize the intermetallic phases and provide micrographs for subsequent image analysis.

The micrographs were analyzed for intermetallic layer thickness at the substrate/solder interface. Average thickness measurements were made using Image-Pro Plus software by dividing the area of the interfacial intermetallic layer by its length. The accuracy of this average measurement was estimated to be $\pm 0.25 \mu \mathrm{m}$, dictated by the ability to resolve this boundary in the magnified images. At least two measurements were made for each specimen and condition.

The mechanical test specimens were produced in the following way. $\mathrm{Cu}$ plates were machined to produce symmetrical substrates of dimensions $60 \mathrm{~mm} \times 20 \mathrm{~mm} \times 1 \mathrm{~mm}$. A rectangular butt joint was then produced by affixing the substrates in a custom soldering jig that fixed the gap thickness to $0.5 \mathrm{~mm}$, chosen to keep the influence of constraining effects on the resulting mechanical response of the solder joint to a minimum. ${ }^{11}$ The three solder pastes of interest were prepared as previously described, and used as a filler material between the fixed substrates. The solder was reflowed, and joints produced, by placing the entire soldering assembly (jig with affixed substrates and solder) in the reflow oven and subjecting it to an identical temperature profile as that apphed to the aging specimens. Once removed from the jig, the test specimens were ground to remove any excess solder and to fix the width of the joining layer to approximately $0.98 \mathrm{~mm}$ (Fig. 1). The resulting specimens were then portioned to receive isothermal heat treatments again identical to the $24 \mathrm{~h}$ condition of the aging specimens. A total of 24 specimens were produced: four for each solder and aging condition.

The specimens were tested in uniaxial tension. All testing was performed by using an Instron 5848 Micro Tester at a displacement rate of $30 \mu \mathrm{m} / \mathrm{min}$. A sequence of high-resolution images of the joints was recorded during the test through an optical microscope at magnifications of $24 \times$ to $48 \times$. The recorded sequences were then processed in custom-developed digital image correlation (DIC) software to calculate the evolution of the average strain in the solder during the test. ${ }^{8}$ This technique enables strain resolution in the joint of approximately $0.02 \%$.

\section{RESULTS}

The synthesized copper oxide particles were confirmed to be $\mathrm{Cu}_{2} \mathrm{O}$ by powder x-ray diffraction (XRD) (Fig. 2). The five peaks of the $\mathrm{x}$-ray spectrum 


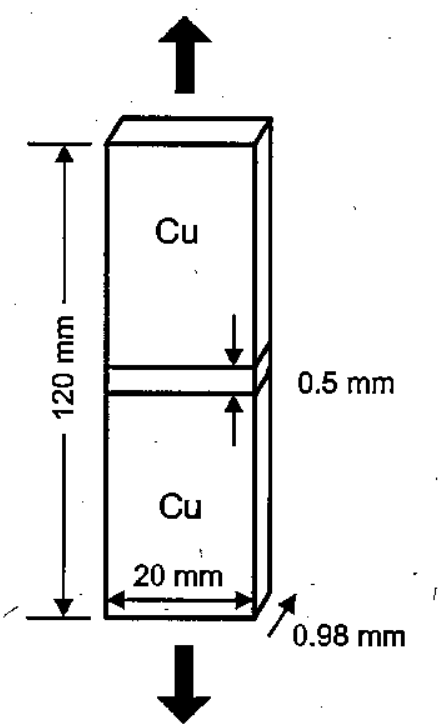

Fig. 1. Schematic of mechanical test specimen and loading direction.

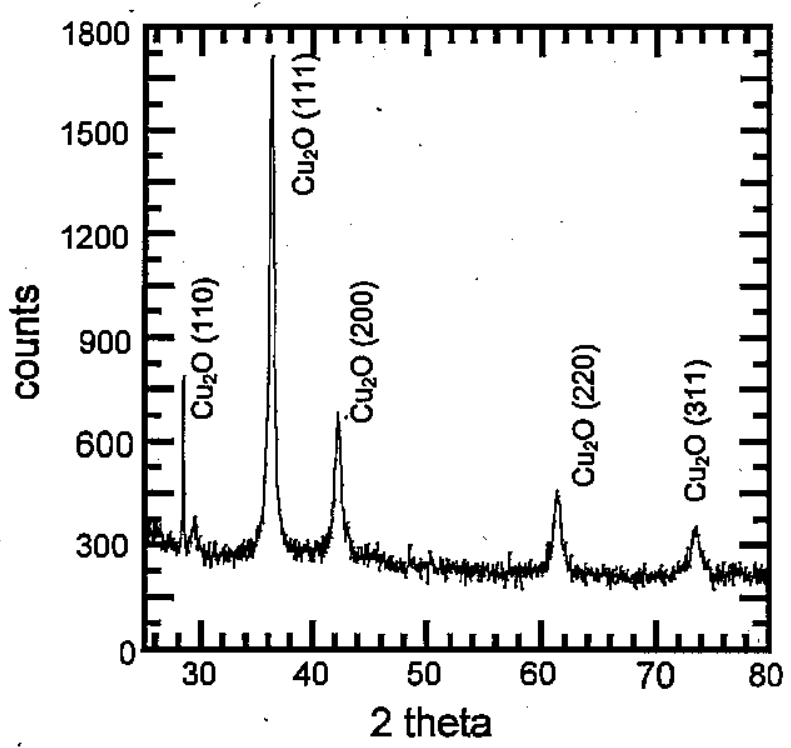

Fig. 2. XRD pattern for synthesized nanometer-scale $\mathrm{Cu}_{2} \mathrm{O}$ particles.

correspond to the interplanar spacings of $3.02 \AA$, $2.46 \AA, 2.13 \AA, 1.5 \AA$, and $1.28 \AA$, consistent with the $\mathrm{Cu}_{2} \mathrm{O}$ cubic phase powder diffraction standard. ${ }^{12}$ The lattice constant calculated for this set of planes is $4.25 \AA$, a value in agreement with $\mathrm{Cu}_{2} \mathrm{O}$. ${ }^{13}$

Transmission electron microscopy (TEM) images illustrated that the particles were of cubic morphology and the associated electron diffraction pattern confirmed their single-crystalline nature (Fig. 3). Also visible in the TEM image is the protective PVP cap, appearing as a hight halo around the cubic particle. From similar images the mean particle diameter was estimated to be roughly $150 \mathrm{~nm}$ and of narrow distribution.
Hereafter the three aging specimens are referred to as follows: unreinforced reference alloy (SAC405), composite with micrometer-scale $\mathrm{Cu}$ particles $(\mu \mathrm{mCu}+\mathrm{SAC} 405)$, and composite with nanometerscale $\mathrm{Cu}_{2} \mathrm{O} / \mathrm{PVP}$ particles ( $\left.\mathrm{nmCu}+\mathrm{SAC} 405\right)$. The SAC405 specimen contained three phases upon solidification: a matrix phase and two second phase particles (Fig. 4a). EDS analyses of these phases yielded compositions in weight percent of $\mathrm{Sn}-4.0 \mathrm{Ag}$, $\mathrm{Sn}-73 \mathrm{Ag}$, and $\mathrm{Sn}-40 \mathrm{Cu}$, surmised to be (Sn), $\mathrm{Ag}_{3} \mathrm{Sn}$, and $\mathrm{Cu}_{6} \mathrm{Sn}_{5}$, respectively. The $\mathrm{Ag}_{3} \mathrm{Sn}$ was organized as a fine needle-like phase within the ( $\mathrm{Sn}$ ) matrix. The $\mathrm{Cu}_{6} \mathrm{Sn}_{5}$ was observed as both a small fraction of fine particles within the matrix and as a scalloped interfacial layer with the $\mathrm{Cu}$ substrate. The average thickness of this $\mathrm{Cu}_{6} \mathrm{Sn}_{5}$ interfacial intermetallic was measured to be $1.4 \mu \mathrm{m}$. Though the $\mathrm{Cu}_{3} \mathrm{Sn}$ intermetallic is also expected at this interface, it was not resolvable for any of the specimens in the as-soldered condition, an observation in agreement with similar studies. ${ }^{14}$ For the $\mu \mathrm{mCu}+\mathrm{SAC} 405$ composite specimen a bulk microstructure of the solder alloy with large $\mathrm{Ag}_{3} \mathrm{Sn}$ platelets randomly dispersed in the (Sn) matrix was observed. Larger $\mathrm{Ag}_{3} \mathrm{Sn}$ platelets extending up to tens of micrometers were found primarily in the vicinity of the $\mathrm{Cu}$ reinforcements. The mechanically introduced micrometer-scale $\mathrm{Cu}$ particles had also reacted with the solder alloy to form a surrounding $\mathrm{Cu}_{6} \mathrm{Sn}_{5}$ layer similar to that formed with the $\mathrm{Cu}$ substrate (Fig. 5a). The average intermetallic layer thickness at the substrate/solder interface was $1.5 \mu \mathrm{m}$. Additionally, pores up to $5 \mu \mathrm{m}$ in diameter were observed and unique to this specimen. In the $n m C u+$ SAC405 specimen a fine $\mathrm{Ag}_{3} \mathrm{Sn}$ needle-hike network comparable with that seen in the SAC405's microstructure was observed. Additionally the $\mathrm{Cu}_{2} \mathrm{O} / \mathrm{PVP}$ nanometer-scale particles appear to have completely transformed into the $\mathrm{Cu}_{6} \mathrm{Sn}_{5}$ phase (Fig. 6). It is hypothesized that the aggressive flux used during reflow had reduced the copper oxide to copper metal, which subsequently reacted with the solder alloy to form the intermetallic. There was also no evidence of PVP, or its decomposition products, within the bulk of the reflowed solder, though a shght black residue was present on the solder surface that easily washed off following the initial reflow. The average diameter of these particles was roughly $3.5 \mu \mathrm{m}$. The average $\mathrm{Cu}_{6} \mathrm{Sn}_{5}$ layer thickness at the substrate/solder interface for the $\mathrm{nmCu}+\mathrm{SAC} 405$ specimen was measured to be $1.9 \mu \mathrm{m}$.

The aging specimens were re-examined following each heat treatment for interfacial intermetallic layer thickness and microstructural evolution. The interfacial $\mathrm{Cu}_{3} \mathrm{Sn}$ phase was only prominent after the first aging interval of $24 \mathrm{~h}$ for all specimens. For the SAC405 specimen the fine needle-like $\mathrm{Ag}_{3} \mathrm{Sn}$ network observed in the as-soldered condition had been transformed into larger, randomly dispersed $\mathrm{Ag}_{3} \mathrm{Sn}$ particles within the (Sn) matrix (Fig. 4b). 
Interfacial Intermetallic Growth and Strength of Composite

Lead-Free Solder Alloy Through Isothermal Aging
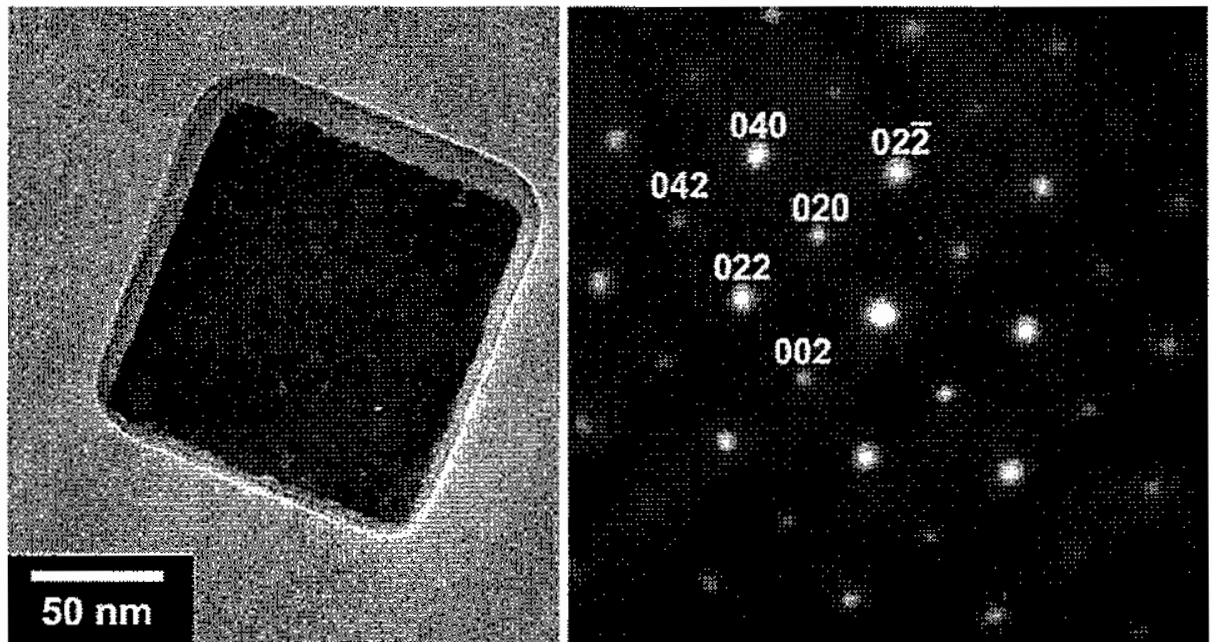

Fig. 3. TEM image and diffraction pattern of the synthesized nanometer-scale $\mathrm{Cu}_{2} \mathrm{O}$ particles.
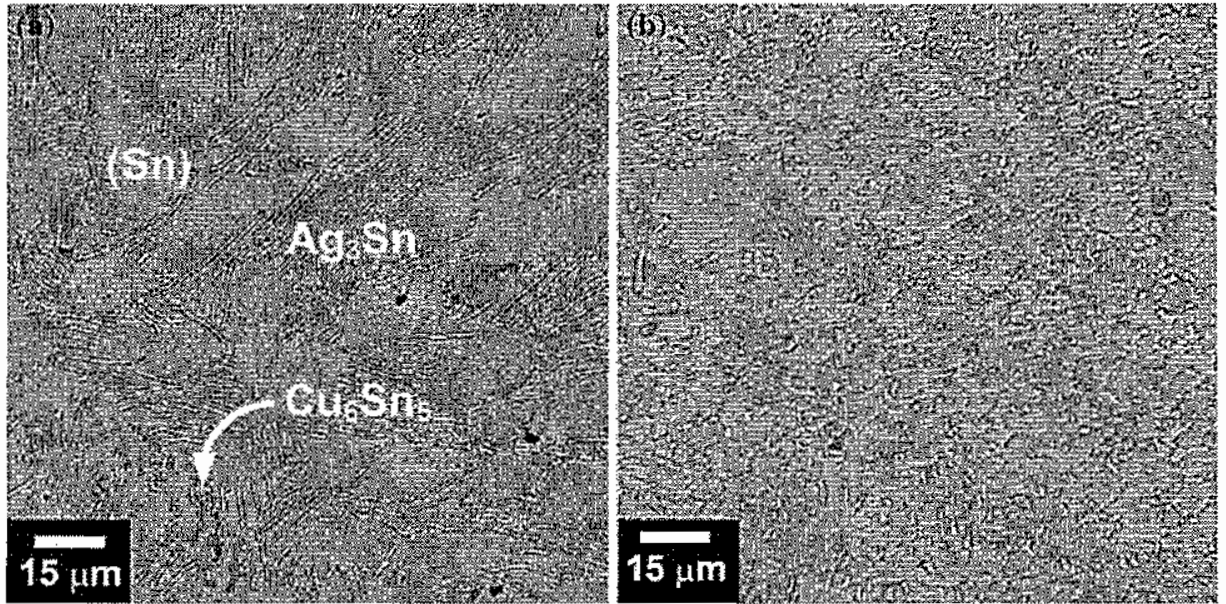

Fig. 4. Backscatter SEM image of the SAC405 specimen in the (a) as-soldered condition and (b) following $144 \mathrm{~h}$ at $150^{\circ} \mathrm{C}$.
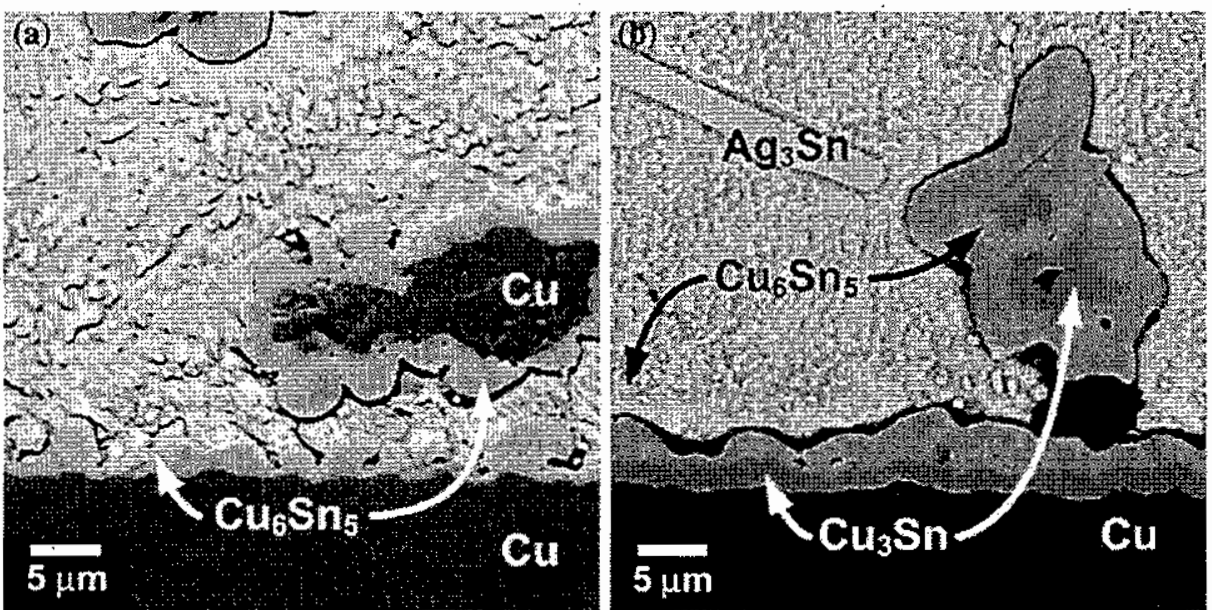

Fig. 5. Backscatter SEM image of the $\mu \mathrm{mCu}+\mathrm{SAC} 405$ specimen at the solder/substrate interface in the (a) as-soldered condition and (b) following $144 \mathrm{~h}$ at $150^{\circ} \mathrm{C}$. 


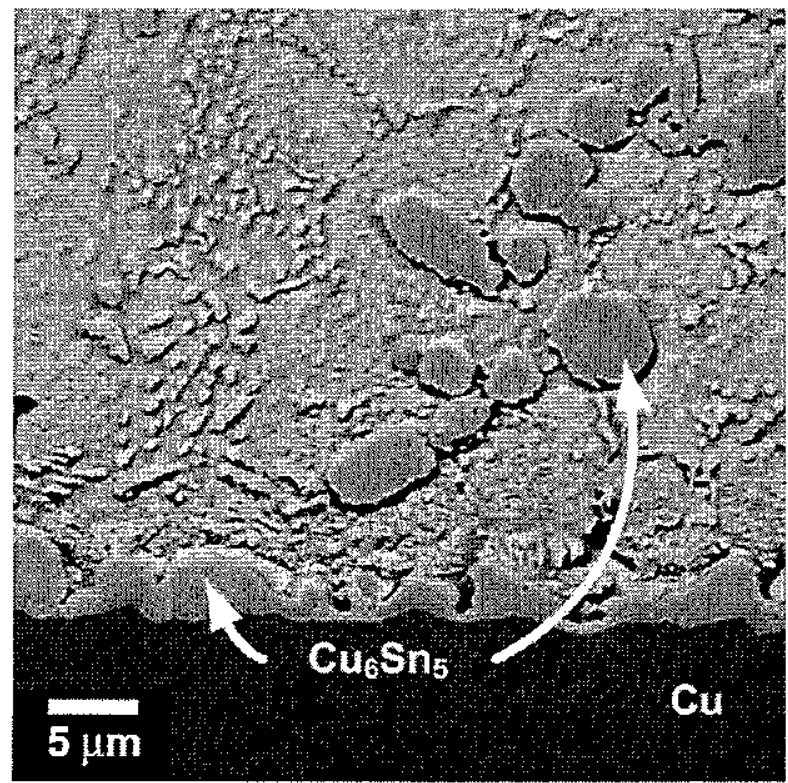

Fig. 6. Backscatter SEM image of the $\mathrm{nmCu}+\mathrm{SAC} 405$ specimen at the solder/substrate interface in the as-soldered condition.

At the substrate/solder interface, the valleys that were also initially present in between the intermetallic scallops in the as-soldered condition had filled to form a more uniformly thick layer. The total $\left(\mathrm{Cu}_{3} \mathrm{Sn}+\mathrm{Cu}_{6} \mathrm{Sn}_{5}\right)$ layer thickness for the $\mathrm{SAC} 405$ specimen after $144 \mathrm{~h}$ of aging was $4.1 \mu \mathrm{m}$. In the $\mu \mathrm{mCu}+\mathrm{SAC} 405$ specimen, after aging for $24 \mathrm{~h}$, the transformation of the $\mathrm{Cu}$ reinforcements in to $\mathrm{Cu}-\mathrm{Sn}$ intermetallics had increased. Further aging to $144 \mathrm{~h}$ increased the consumption of $\mathrm{Cu}$ particles by the solder matrix to form a thicker $\mathrm{Cu}_{6} \mathrm{Sn}_{5}$ surrounding layer (Fig. $5 \mathrm{~b}$ ). The morphology of the interfacial intermetallic at the substrate/solder interface also evolved in a similar fashion to the SAC405 specimen. This total layer thickness was $3.9 \mu \mathrm{m}$ at the conclusion of the $144 \mathrm{~h}$ of aging, slightly lower than that measured for the SAC 405 specimen. For the nmCu + SAC405 specimen, the original fine $\mathrm{Ag}_{3} \mathrm{Sn}$ network evolved similarly to the SAC405 sample to form a coarser structure in the (Sn) matrix. The interfacial intermetallic layer also evolved to be more uniform, with a thickness of $3.8 \mu \mathrm{m}$.

The stress-strain responses of the joints for the assoldered and aged condition are presented in Figs. 7 and 8 , respectively. The solid bulleted curves represent the average stress-strain response of at least three identical specimens. The gray shading represents the range in the measurement: The mechanical response for the specimens tested in the as-soldered condition was very similar for the SAC405 and $\mathrm{nmCu}+\mathrm{SAC} 405$ specimens. The $\mu \mathrm{mCu}+\mathrm{SAC} 405$ specimen, however, exhibits a significantly lower ultimate tensile stress (34.5 MPa) when compared with SAC405 (43.4 MPa) and

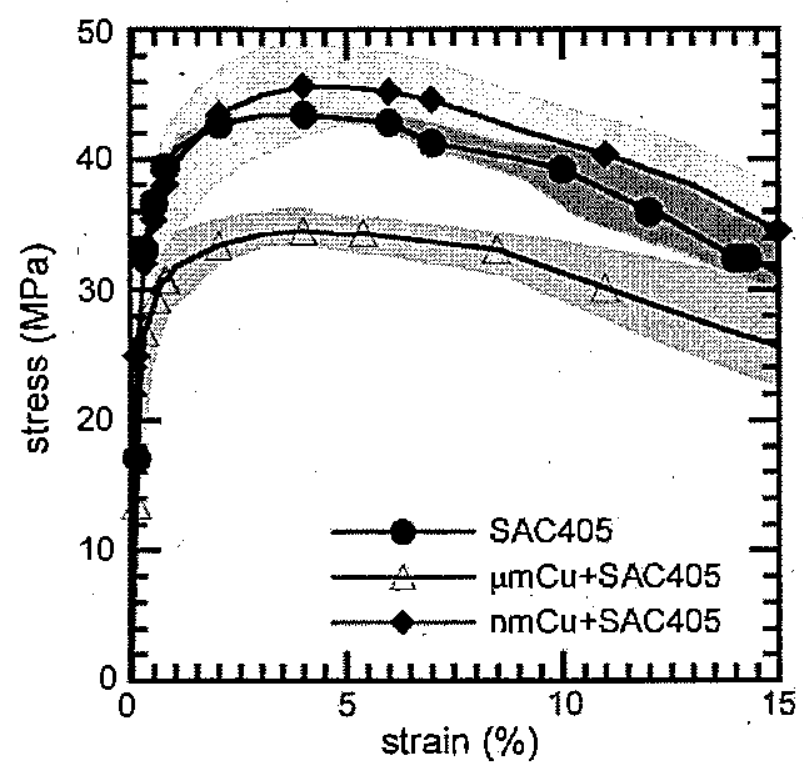

Fig. 7. Tensile stress response for the solders in the as-soldered condition.

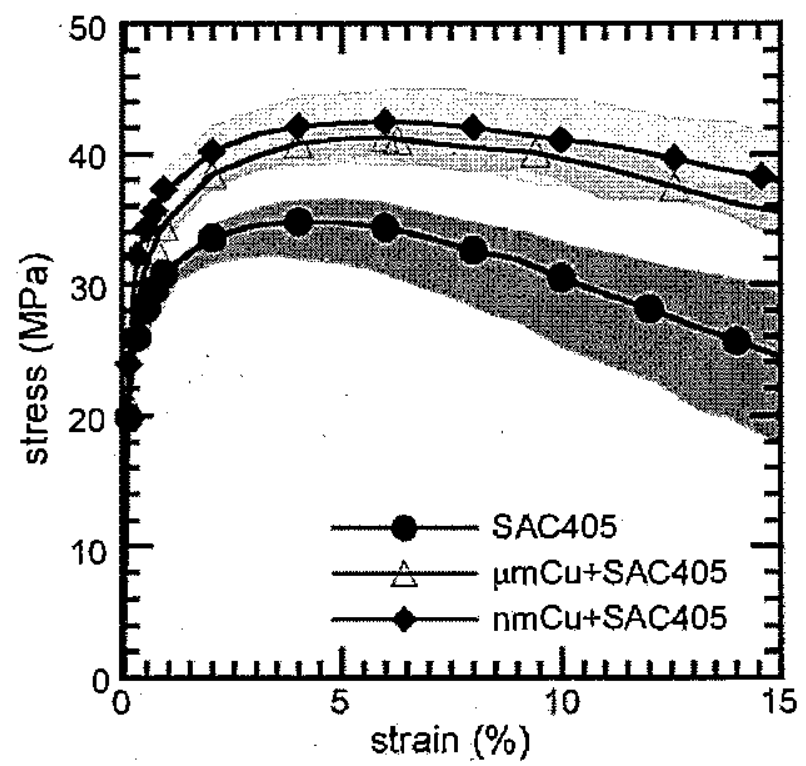

Fig. 8. Tensile stress response for the solders following $24 \mathrm{~h}$ of aging.

$\mathrm{nmCu}+\mathrm{SAC} 405$ (45.6 MPa). In the aged condition the SAC405 specimen's ultimate tensile stress decreased to $34.8 \mathrm{MPa}$, and the $\mu \mathrm{mCu}+\mathrm{SAC} 405$ specimen's increased to $41.2 \mathrm{MPa}$, comparable with that of the aged $\mathrm{nmCu}+\mathrm{SAC} 405$ specimen (42.3 $\mathrm{MPa}$ ) whose mechanical response appeared to be stable through aging. The ductility of the composite specimens also appeared to be unaffected by the presence of the additional reinforcing phase. 


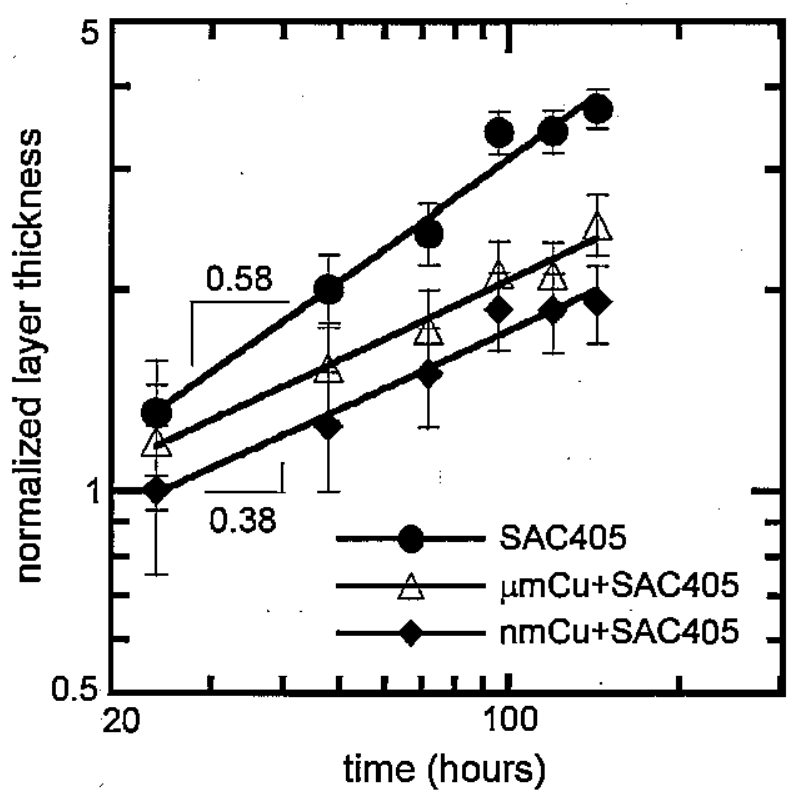

Fig. 9. Normalized interfacial intermetallic layer thickness as a function of aging time.

\section{ANALYSIS AND DISCUSSION}

The normalized intermetallic layer thickness at the substrate/solder interface, plotted on a logarithmic scale, are presented in Fig. 9 . Since it is the intention of the present study to evaluate the effect of aging on the interfacial intermetallic layer thickness, the measured thickness has been normalized with respect to the as-soldered thickness for comparison between specimens and subsequent analysis. (It is reasonable to expect that small differences in heating and cooling rates and the time during which the solder was molten between specimens could result in large differences in the initial layer thickness. ${ }^{15}$ Furthermore, addition of the $\mathrm{Cu}$ particles in the composite specimens could have also influenced the solidification temperature, exacerbating this effect. ${ }^{16}$ ) For aging times larger than $24 \mathrm{~h}$, the average thickness follows a power law with aging time with a growth exponent of $0.58,0.39$, and 0.38 for $\mathrm{SAC} 405, \mu \mathrm{mCu}+\mathrm{SAC} 405$, and $\mathrm{nmCu}+$ SAC405, respectively. The separation of the similarly sloped curves for the two composite specimens suggests that a steady state in the growth exponent. was not immediately achieved, and therefore the power-law fit would not be valid for shorter times. Additionally, the lower-lying data set for the $\mathrm{nmCu}+\mathrm{SAC} 405$ specimen suggests it had reached its steady-state growth exponent sooner than the $\mu \mathrm{mCu}+\mathrm{SAC} 405$ specimen.

The growth exponent value of 0.58 for the SAC405 specimen is in agreement with similar works and is indicative of bulk diffusion as the rate-limiting mechanism. ${ }^{17}$ The suppression of the interfacial intermetallic layer's growth exponent for the composite solders suggests that the presence of the additional copper either changes the diffusional mechanism or is in some other way responsible for its reduction. A growth exponent on the order of 0.33 , similar to that experienced for the composite solders of this study, is more indicative of a grainboundary-dominant diffusion as the rate-limiting mechanism. ${ }^{18}$ Other hypotheses for the mechanism of growth exponent reduction include the additional $\mathrm{Cu}$ particles (i) acting as Sn sinks, thereby reducing the amount of Sn available for the interfacial reaction and (ii) acting as physical obstacles, consequently reducing the cross-sectional area available for Sn diffusion. ${ }^{19}$

The similar steady-state growth exponent for the composite solders and the appearance that the $n m \mathrm{nu}+\mathrm{SAC} 405$ specimen was first to achieve this steady state provides a basis for further speculation on the rate-limiting mechanism. First, while the $\mathrm{nmCu}+\mathrm{SAC} 405$ specimen was fabricated with nanometer-scale $\mathrm{Cu}_{2} \mathrm{O} / \mathrm{PVP}$ particles, they were quickly converted to micron-sized intermetalhic inclusions following the initial reflow. Therefore it is reasonable to expect they might have the same overall effect as the micrometer-scale $\mathrm{Cu}$ particles employed in the $\mu \mathrm{mCu}+\mathrm{SAC} 405$ specimen, at least for longer aging times. This is indeed what is currently observed, exemplified by the similar steady-state growth exponent for the two composite specimens. The observation that the $\mathrm{nmCu}+$ SAC405 specimen was first to achieve this steady state may then be attributed to the primary difference between the composite specimens: the time to total conversion of the primary particles to the stable $\mathrm{Cu}_{6} \mathrm{Sn}_{5}$ phase. Since the $\mathrm{Cu}_{2} \mathrm{O} / \mathrm{PVP}$ particles where converted first and almost completely upon initial reflow, the hypothesis that the particles act as Sn sinks, thereby precluding the full availability of $\mathrm{Sn}$ at the substrate/solder interface, is not supported by the current results. However, the hypothesis that the additional particles act as physical obstacles to $\mathrm{Sn}$ diffusion towards this interface is reinforced. Since the $\mathrm{Cu}_{2} \mathrm{O} / \mathrm{PVP}$ particles were quickly converted to the $\mathrm{Cu}_{6} \mathrm{Sn}_{5}$ phase their maximum volume, and therefore ability to obstruct, was achieved early, providing for an associated early onset of the steady-state growth exponent. Conversely the micrometer-scale $\mathrm{Cu}$ particles took longer for their conversion, and therefore attainment of their maximum volume, thereby delaying the onset of a similar steady-state growth exponent.

The trends in specimen strength may be rationalized by considering their microstructure and microstructural evolution through aging. In the as-soldered condition, the two specimens with the similarly high ultimate tensile strength (SAC405 and $\mathrm{nmCu}+\mathrm{SAC} 405$ ) also share a similar microstructural feature: the fine needle-like distribution of the $\mathrm{Ag}_{9} \mathrm{Sn}$ phase in the (Sn) matrix. In the $\mu \mathrm{mCu}+\mathrm{SAC} 405$ specimen, however, this structure 
is absent as the $\mathrm{Ag}_{3} \mathrm{Sn}$ is arranged as a coarser phase. Similar studies have also observed higher tensile strengths when the $\mathrm{Ag}_{3} \mathrm{Sn}$ particles are more finely dispersed, ${ }^{20}$ Following aging the fine structure of the $\mathrm{Ag}_{3} \mathrm{Sn}$ phase in both the $\mathrm{nmCu}+$ SAC405 and SAC405 specimens coarsens, however only the tensile strength of the SAC405 sample decreases. Furthermore, the strength of the $\mu \mathrm{mCu}+\mathrm{SAC} 405$ specimen increases to a value comparable with that of the $\mathrm{nmCu}+\mathrm{SAC} 405$ specimen, even though the $\mathrm{Ag}_{3} \mathrm{Sn}$ phase remains as larger platelets. The common feature in the aged condition between the similarly highly strengthened $\mathrm{nmCu}+\mathrm{SAC} 405$ and $\mu \mathrm{mCu}+\mathrm{SAC} 405$ specimens is the presence of the additional $\mathrm{Cu}_{6} \mathrm{Sn}_{5}$ phase. Unlike in the $\mathrm{nmCu}+\mathrm{SAC} 405$ specimen, whose strength starts and remains high, the additional aging of the $\mu \mathrm{mCu}+\mathrm{SAC} 405$ specimen is required to increase the amount of $\mathrm{Cu}_{6} \mathrm{Sn}_{5}$ to a level which similarly impacts its mechanical behavior.

\section{CONCLUSION}

The microstructural evolution and strength of joints produced with. SAC405 lead-free solder depends significantly on reinforcing particle. Solders reinforced with both micrometer- and nanometer-scale reinforcements appear to have reduced the interfacial intermetallic growth rate when compared with unreinforced solder. Furthermore, while a similarly reduced steady-state growth rate exponent is achieved, it is reached first when the reinforcements start as nanometer-scale particles. This behavior is attributed to the smaller reinforcements fully transforming into their equilibrium intermetallic phase before the larger particles. The solder reinforced with the nanometer-scale particles also exhibited the highest strength both before and after aging, without an associated sacrifice in ductihty. The unique behavior of this composite comes despite its initially nanometer-scale reinforcements growing to micrometer-scale particles through reflow. The ability to maintain the nanometer scale of the reinforcement may further benefit the properties of this composite solder, and should therefore be considered an outstanding issue for additional work.

\section{ACKNOWLEDGEMENT}

This research was performed in the framework of COST 531 Action: Lead-Free Solder Materials and was supported by the Swiss State Secretariat for Education and Research (SER) Grant C03.0026.

\section{REFERENCES}

1. M. Abtew and G. Selvaduray, Mater. Sci. Eng. R-Rep. 27, $95(2000)$.

2. K.N. Tu, A.M. Gusak, and M. Li, J. Appl. Phys. 93, 1335 (2003). doi:10.1063/1.1517165.

3. K.N. Subramanian and G. Lee, J. Mater. 55, 26 (2003).

4. D.R. Frear and P.T. Vianco, Metall Mater. Trans. A-Phys. Metall. Mater. Sci. 25A, 1509 (1994). doi:10.1007/BF0266 5483.

5. S.T. Kao, Y.C. Lin, and J.G. Duh, J. Electron. Mater. 35,486 (2006). doi:10.1007/BF02690536.

6. F. Guo, J. Mater. Sci. Mater. Electron. 18, 129 (2007) doi:10.1007/s10854-006-9019-1.

7. S. Choi, J.G. Lee, F. Guo, T.R. Bieler, K.N. Subramanian, and J.P. Lucas, JOM 53, 22 (2001).

8. F. Guo and K.N. Subramanian, Adv. Mater. Process. 160(12), 41 (2002).

9. J.G. Lee, F. Guo, K.N. Subramanian, and J.P. Lucas, Solder Surf. Mount Tech. 14, 11 (2002). doi:10.1108/095409102104 27772.

10. C. Chen, L. Wang, G.H. Jiang, and H.J. Yu, Rev. Adv. Mater. Sci. 11, 1 (2006).

11. J. Cugnoni, J. Botsis, V. Sivasubramaniam, and Janczak Rusch, Fatigue Fract. Eng. Mater. Struct. 30, 387 (2007). doi:10.1111/1460-2695.2006.01077.x.

12. JCPDS. File No. 75-1531 (Joint Committee on Powder Diffraction Standards, Swarthmore, PA).

13. L.H. Germer, Phys. Rev. 52, 0959 (1937).

14. S. Choi, T.R. Bieler, J.P. Lucas, and K.N. Subramanian, J. Electron. Mater. 28, 1209 (1999). doi:10.1007/s11664-9990159-y.

15. X. Deng, G. Piotrowski, J.J. Williams, and N. Chawla, J. Electron. Mater. 32, 1403 (2003). doi:10.1007/s11664-0030108-0.

16. D.C. Lin, T.S. Srivatsan, G.X. Wang, and R. Kovacevic J. Mater. Eng. Perform. 16, 647 (2007). doi:10.1007/sI1665007-9092-5

17. Z. Mei, A.J. Sunwoo, and J.W. Morris, Metall. Trans. A-Phys. Metall. Mater. Sci. 23, 857 (1992).

18. M. Schaffer, W. Laub, J.M. Sabee, and R.A. Fournelle, J. Electron. Mater. 25, 992 (1996) doi:10.1007/BF02666735

19. Y. Wu, J.A. Sees, C. Pouraghabagher, L.A. Foster, J.I Marshall, E.G. Jacobs, and R.F. Pinizzotto, J. Electron. Mater. 22, 769 (1993). doi:10.1007/BF02817353.

20. Y. Ding, C.Q. Wang, Y.H. Tian, and M.Y. Li, J. Alloy. Compd. 428, 274 (2007). 